\title{
0 encontro trabal hador-usuário na atenção à saúde: uma contribuição da narrativa psicanalítica ao tema do sujeito na saúde coletiva
}

The healthcare professional-patient relationship: a contribution of psychoanalytic narrative to the issue of the subject in public health

A bstract It is our purpose, in this work, to debate the relationship between workers and patients in the clinic context. U sing a hermeneutic and narrative approach, we shall discuss some narrative lines in order to situate the present study. We offer some psychoanalytic and institutional psychotherapy categories, as a tool for rethinking this relationship, in their institutional, clinic, and managing aspects. In the end, following K risteva, a linking between text, narrative and experience is proposed.

Key words Collective health, M anagement-subjectivity, H ermeneutic critic, Narrative, Clinics, Psychoanalysis
Resumo Neste trabalho procurou-se problematizar o tema do encontro assistencial entre usuários e trabalhadores de saúde. U tilizando uma abordagem hermenêutico-crítica e narrativa mapeiam-se brevemente algumas linhas narrativas visando situar em relação a elas o tema em estudo. O ferecem-se al gumas categorias oriundas da psicanálise e da psi coterapia institucional para repensar a dimensão do encontro profissionalusuário, nas suas relações com a instituição, a clínica, 0 acolhimento e a gestão. No final, a partir das elaborações de K risteva, propõe-se uma ligação metodológica entre texto-narrativa e experiência.

Palavras-chave Saúde coletiva, Gestão-subjetividade, Hermenêutica crítica, N arrativa, Clínica, Psicanálise 


\section{Introdução: abordagem hermenêutica crítica e narrativa}

Escrever sobre os encontros é encarar o próprio paradigma da escrita. Toda escrita é ao mesmo tempo um encontro e um desencontro. $E$ toda escrita somente poderá surgir de al gum encontro. Ensina-nos Paul Ricoeur que todo texto "é a vinda à linguagem de um mundo" (1990). Portanto, concordando com ele, diríamos que não há escrita que não tenha sido provocada, produzida, pela vida real e concreta, ao menos para quem escreve.

$\mathrm{N}$ a sua proposta de uma hermenêutica crítica, Ricoeur (1990) faz algumas proposições, visando superar a divisão entre teórica crítica e hermenêutica. Sua obra interessa-nos por produzir uma reconexão entre escolas do pensamento que em muito contribuíram metodologicamente nas últimas décadas para al guns dos principais trabalhos da saúde coletiva brasileira.

Achamos que há inovações importantes trazidas por Ricoeur (op. cit.), pois ele propõe uma síntese diferente, com interessantes pontos de sutura, que não separam a crítica da hermenêutica, porém destacam a inegável potência da crítica, de certa forma sempre já implicada no exercício hermenêutico.

A empreitada de Ricoeur parte, fundamentalmente, da Escola de Frankfurt (como expoente da teoria crítica, e notadamente da crítica de H abermas a Gadamer), e das elaborações sobre hermenêutica realizadas por Gadamer em Verdade e método.

Dentre as principais contribuições de Gadamer (1997) nessa obra, destacam-se as de "mundo do texto", "história efeitual", "tradição", e o reconhecimento da função positiva, como mola do movimento hermenêutico, dos "preconceitos". Se H abermas critica que o conceito de tradição é conservador (pois a tradição é assentada sobre séculos de dominação, poder e trabalho), Gadamer também argumenta que é clássico aquilo que permanece em face da crítica histórica. Talvez, poderíamos dizer, hoje, que nossos clássicos mantêm-se vigentes, pois falam de algo que se repete. Psicanaliticamente diríamos: os clássicos falam de nossa neurose no contemporâneo. Gadamer destaca o fato de que, ao lermos um clássico, ele reatualiza-se na leitura, parecendo que diz algo especificamente dirigido a quem o lê. Isso é o que Ricoeur chama de agenciamento formal do texto. 0 mais importante - nos diz ele - não é procurar segredos por trás do texto, pois inter- pretar nada mais é que "explicitar o tipo de serno-mundo manifestado na frente do texto" (Ricoeur, 1990).

Com Freud (1975) e Roudinesco e Plon (1998), trabalhamos a interpretação como composta sempre de dois movimentos: a análise e a construção. Às construções - que fazem, no dizer de Freud, uma espécie de aposta na produção de sentido, a vinda à tona de uma nova história - chamamos, junto com Ricoeur, de narrativas. As narrativas, para este autor, nada mais são do que "o agenciamento dos fatos, histórias não (ainda) narradas" (Ricoeur, 1997), mas que se podem ser contadas, é porque estão já inseridas em alguma práxis social. N essa linha, o que caracteriza uma narrativa fundamentalmente é sua linha argumental, o muthos: agenciamento dos fatos.

Em trabalho anterior (Onocko Campos, 2003a), consideramos que, antes de assistir a uma mudança paradigmática (Kuhn, 1997), conseguiríamos descobrir o aparecimento de novas narrativas disciplinares. Talvez possamos pensar a transição paradigmática como uma fase que poderia ser preferencialmente estudada com a abordagem narrativa. Em relação ao tema em estudo, arriscamos a hipótese de se tratar de um momento de mudança nas abordagens clássicas sobre a subjetividade na atenção à saúde, no campo da saúde coletiva brasileira.

No contexto da atenção à saúde, o tema dos encontros profissionais/usuários é clássico e ao mesmo tempo novo no seu enfoque: " (...) o veIho e o novo crescem sempre juntos para uma validez vital (...)" (Gadamer, 1997). Tentaremos fazer uma análise hermenêutico-crítica desse tema. Para isso, procuramos primeiro fazer uma reflexão sobre o tema dos encontros, para depois fazer um breve percurso por algumas linhas narrativas que nas últimas décadas problematizaram a questão. Voltamos a seguir ao contemporâneo, às grandes cidades brasileiras, suas periferias e o contexto do SUS, buscando aproximar algumas reflexões advindas da psicanálise ao cenário atual. Ao final, recorremos à Julia Kristeva e sua conceituação da experiência e da narrativa política à guisa de conclusão provisória.

\section{0 que é um encontro?}

Diz o dicionário que encontro é o ato de encontrar. E que encontrar é: deparar com, achar, dar com, atinar com, descobrir, achegar, unir, 
mas também opor-se a, contrariar, chocar-se com (Ferreira, 1997). Pôr-se em contato, portanto, sempre com resultado incerto. 0 encontro pode ser cordial ou podeser um rijo encontrão. Quem se contata com quem? Corpos e afetividades em jogo. Se entendermos por instituições as formações discursivas que adquiriram valor de verdade, quantas instituições mediam esse encontro quando se trata de uma situação de atenção à saúde?

$N$ a saúde coletiva costumamos lembrar que o usuário sempre comparece a esse encontro movido por demandas mais ou menos explícitas, munido de seu corpo e sua singular subjetividade. M as, são muito menos freqüentes os estudos que procuram analisar o que acontece com esse sujeito que um dia se transformou, por obra da academia, ou da vida, em um trabalhador de saúde. Categoria que propositalmente, por enquanto, preferiremos manter assim, ampla e mal definida de maneira que, neste ponto de nosso estudo, caibam nela desde profissionais universitários até agentes de saúde e pessoal da recepção. Isto não pressupõe apagar suas diferenças em relação às divisões técnicas e sociais do trabalho, mas manter aberta a possibilidade de pensar alguns aspectos da subjetividade dessas pessoas que, com graus de qualificação diversos, compartilham o espaço de trabal ho nos serviços de saúde.

\section{Algumas linhas narrativas que pensaram esse encontro}

Pretendemos a seguir mapear algumas linhas narrativas, não com o objetivo de fazer um estudo exaustivo ou historiografia, porém com 0 intuito de poder situar em relação a elas nossa própria contribuição narrativa, (...) num sentido verdadei ramente hermenêutico, isto é, com a atenção posta no que foi dito: a linguagem em que nos fala a tradição, a saga que ela nos conta (Gadamer, 1997). Portanto, procuraremos nelas os traços fundamentais de uma estrutura argumentativa e ilustrá-las-emos com alguns exemplos de autores, sem desconsiderar que 0 rico universo de produção dessas linhas narrativas é muito mais amplo do que pode ser abordado neste estudo.

Para tentar situar nossa própria produção, é importante recuperar na tradição a linha que chamarei de "medicina social latino-americana", cujo marco, segundo Fleury (1992), foi a Conferência de Cuenca. Ali houve uma clara crítica à forma predominante de organização da prática médica. Desde os estudos de Juan César García sobre educação médica, passando pelo termo cunhado por M enendez (1992) "modelo médico hegemônico" - , a crítica aprofundou-se com a entrada em cena das ciências sociais na área da saúde, dedicando uma grande parte de sua produção, nas décadas de 19701980 , a questionar o positivismo vigente, a denunciar a falta de consideração de outras categorias e adentrando-se ferrenhamente num certo furor preventivista de viés histórico-estrutural.

Como destaca Fleury, o paradigma histórico-estrutural no campo da saúde, partindo do reconhecimento da insuficiência das teorias precedentes para darem conta da explicação dos determinantes do processo de saúde e doença e da organização social da prática médica, procurou na relação entre medicina e estrutura social o caminho para tais explicações (1992). Essa linha não produziu estudos sobre o encontro assistencial que incluíssem o corpo e a subjetividade de profissionais e de usuários como categorias de análise.

É a partir da medicina social latino-americana que a "saúde coletiva brasileira" (O nocko Campos, 2003a) conforma-se como uma linha narrativa original que desabrocha em uma rica produção teórica, em núcleos de pós-graduação e pesquisa e em elaborações originais que pouco a pouco a diferenciam, por sua riqueza e volume, da produção latino-americana.

Duas décadas passadas, essa linha conta no seu acervo com clássicos (no sentido gadameriano) do peso de Cecília Donnangelo (1975) e Sergio Arouca (2003). Não é o propósito deste artigo fazer uma análise exaustiva dos numerosos autores da saúde coletiva brasileira, porém pretendemos, ancorados nesses dois exemplos, caracterizar a narrativa produzida em relação à subjetividade no encontro assistencial. E é possível vermos, assim, partindo dos estudos pioneiros de Donnangelo sobre o trabalho médico, ou da crítica de Arouca no Dilema preventivista, que pouco se pensava, nos anos 70 , na subjetividade e no corpo dos trabal hadores da saúde e que o tema da clínica ficou fora das análises, a não ser para contrapô-la às ações coletivas. Essa linha, preocupada com a crítica, produziu intensos questionamentos sobre a clínica, a biologização excessiva das práticas e chamou muito bem a atenção para o processo de construção sócio-histórico das categorias operatórias dominantes (Luz, 2000). 
Herdeira do referencial teórico estruturalmarxista, outros trabalhos já mostraram quea saída da hegemonia desse referencial teórico deu-se a partir da incorporação de novos referencias teóricos e metodológicos entre o fim dos anos 70-80 (Burlandy \& Bodstein, 1998), dando entrada a categorias como cotidiano e representação social, na tentativa de alargar o debate em relação às explicações macroestruturais.

É na década de 1990 que essa questão entra na pauta das argumentações de al guns autores. Abordados do ponto de vista do sofrimento dos técnicos (Pitta, 1990) ou da incorporação do tema da clínica (Campos, 1991) sob várias formas de organização (Gonçalvez, 1994), essa temática começa a ser abordada no fim dos anos 80 e tem sido cada vez mais incorporada nos últimos anos (Carvalho, 2003; 2002; M inayo, 1995).

Já a finais dos anos 90, o tema da subjetividade destaca-se e temos, assim, uma produção que começa a argumentar sobre essas questões (Campos, 1994; 2000; Ayres, 2001; M erhy, 1997; Luz, 2000). A discussão sobre a reformulação dos modelos assistenciais, como bem mostram al guns autores, é recente e mais retórica que prática (Vasconcelos, 2005). Em alguns trabaIhos anteriores, argumentamos que a reforma da clínica e a mudança do modelo assistencial são questões importantes de serem encaradas em prol da eficácia do SUS (Onocko Campos, 2003a; 2003b).

Poderíamos afirmar que, no interior da grande narrativa constituída pela saúde coletiva brasileira, al gumas linhas narrativas começam a se diferenciar; elas caracterizam-se precisamente por destacarem nos seus argumentos aspectos pouco explorados pela produção clássi$\mathrm{Ca}$, cujo destaque se produz do encontro com as práticas no SUS, no seu percurso histórico.

Diz Gadamer (1997) que são o presente e os seus interesses os que fazem o pesquisador voltar-se para o passado, para a tradição. Assim, não é de estranhar que no século 21 os autores comecem a problematizar aspectos antes negligenciados.

A partir do tema da subjetividade esboça-se uma preocupação com as instituições de saúde. L'A bbate (2003) mostra que há uma relação entre "análise institucional" e saúde coletiva: há a análise institucional na saúde coletiva e da saúde coletiva; e há também a saúde col etiva como instituição. Contudo, a entrada do chamado - no Brasil - institucionalismo foi muito mais estimulada pelo movimento da Reforma
Psiquiátrica que pelo da Reforma Sanitária (Luz, 2000). Nascidos de um momento político comum, os dois movimentos ora se aproximam, ora se separam (Furtado \& O nocko Campos, 2005). No Brasil, várias correntes como a socioanálise, esquizoanál ise e psicoterapia institucional combinaram-se de formas diversas e pouco ortodoxas para caracterizar o que al guns autores têm chamado de institucionalismo (Rodrigues, 1993).

Todavia, é preciso reconhecer que essas contribuições tiveram relativamente pouca penetração. Talvez seja por se valer de um referencial teórico que não fazia parte das disciplinas clássicas estudadas pel os sanitaristas; o fato é que esse conjunto de referenciais que tem grande potência para pensarmos as relações entre as pessoas e as instituições continua pouco explorado na saúde coletiva até hoje.

\section{Algumas categorias da psicanálise na busca de novas narrativas}

Alguns autores, ainda, transitaram o caminho entre saúde coletiva e "psicanálise" (Birman, 1980; Campos, 1994, 2000; Figueiredo, 1997). A redescoberta do tema do sujeito faz-nos insistir em trilhar esse caminho.

Procuramos aproximar alguns conceitos dessa disciplina e da psicopatologia institucional ao campo da gestão em saúde.

$\mathrm{N}$ a ética que caracteriza a psicanálise, todo sujeito é mais do que portador do cogito cartesiano. A descoberta do inconsciente por Freud marcou uma das grandes quebras da modernidade na opinião de alguns autores (Benasayag $\&$ Charlton, 1993). Assumir que as pessoas, os trabalhadores de saúde, também agem movidas por reações inconscientes, que elas próprias desconhecem, e sobre as quais não detêm o controle mudará nossa forma de abordar os equipamentos de saúde e as relações que ali se desenvolvem. 0 reconhecimento da dimensão inconsciente mudará nossas análises.

Portanto, seria importante neste ponto fazer uma distinção (não sendo uma separação) entre psicanálise e hermenêutica. Para a hermenêutica, lidamos conscientemente o tempo todo com um conjunto de valores de cujo significado não nos damos conta imediatamente, mas ao qual poderíamos aceder por meio da reflexão sistematizada. Para a psicanálise, porém, estaríamos fadados a desconhecer para sempre uma porção de nós mesmos. 0 nosso 
inconsciente irrompe quando menos o esperamos no meio de nossa ação mais racional. Não se trata, portanto, de uma polaridade consciente/inconsciente que se corresponderia com outra racional/irracional, mas de assumirmos 0 ser humano como um ser que nunca será absolutamente dono de si, um ser "barrado" que não pode tudo, e nunca terá a certeza de conhecer apuradamente o rumo do seu desejo.

Alguns autores colocaram em contato a concepção do homem como sujeito do inconsciente e a vida na instituição (Enriquez, 1997; M otta \& Freitas, 2000). Segundo Kaës (1991), a instituição funciona para o psiquismo como asseguradora de funções da vida social e psíquica ( como a mãe) é uma das razões do valor ideal e - necessariamente persecutório - que ela assume tão facilmente.

Ser um trabalhador da saúde, do SUS, e acreditar no valor positivo do próprio trabalho constituem funções estruturantes da subjetividade e ajudam a suportar o mal-estar advindo das tar efas coletivas ( mal-estar inevitável, segundo ensinou Freud, 1997).

Kaës (1991) chama isso de aderência narcísica à tarefa primária. Ou seja, os sujeitos "necessitam" se identificar favoravelmente com a missão do estabelecimento no qual trabal ham, acreditar que seu trabalho tem um valor de uso (Campos, 2000). Quando o contexto de trabaIho coloca entraves à tarefa primária, seja por falta de recursos humanos, de materiais ou por excesso de autoritarismo gerencial (Campos, 2000), os sujeitos valem-se de estratégias defensivas para atenuar o próprio sofrimento psíquico. Algumas delas: apelo excessivo à ideologização, somatização, burocratização, desenvolvimento de estados passionais...

0 termo paixão descreve muito bem o intenso sofrimento psíquico, próximo dos estados psicóticos, que ali [na instituição] se experimenta, é o transbordamento da capacidade de conter e ser contido, a capacidade de formar pensamentos é paralisada e atacada: a repetição, a obnubilação servem de cobertura a ódios devastadores, contra os quais surgem defesas por fragmentação (...) (Kaës, 1991).

Quantas vezes não dizemos da dificuldade das equipes em trabalhar conjuntamente, das fal has de comunicação, do conteúdo excessivamente ideologizado de certas defesas do SU S, em cujo nome, e segundo a ocasião, tudo pode ou tudo não pode?

Tentamos mostrar que esses sintomas institucionais são produzidos pela própria realida- de do trabalho; pelo próprio contato permanente com a dor e a morte e a dificuldade de simbolização que situações como a pobreza extrema nos provocam.

Nos equipamentos de saúde e educação acontecem processos de identificação entre trabalhadores e usuários. Se a população da área de abrangência é vista como pobre, desvalida, desrespeitada, sem valor, após um tempo, a própria equipe se sentirá assim. Pensamos que mecanismos como esse estão por trás da produção de impotência em série de que adoecem muitas equipes de saúde. Também pode acontecer que, na tentativa de se defender desse espelho desagradável, a equipe se feche tentando uma discriminação maior entre o nós e os outros, eassim a equipe monta fortes barreiras que evitam se colocar em contato com aquilo que tanto dói. Ou, pior ainda, pode se tornar agressiva e retaliadora com os usuários.

Se isso éassim, o que lhes receitaremos? Divã para todos os trabalhadores? M aior comunicação (e então como ajudar a comunicar o que permanece inominável?). D oses maiores e deliberadas de boa vontade? Faremos, acaso, mais apelos ideológicos na defesa do SUS?

Lidar competentemente com essas dimensões também requer competência técnica. Ensina-nos Oury (1991) que no trabal ho não se trata simplesmente de relações individuais com alguém, e de que o trabal ho de equipe precisará sempre levar em conta os outros e a si próprio, mas que deve sempre ser tomado no âmbito que lhe é mais específico: um espaço onde "possa acontecer alguma coisa".

Kaës (1991) propõe criar dispositivos de trabal ho que permitam restabelecer um espaço subjetivo conjunto, uma área transicional comum, relativamente operatória.

Temos defendido que a gestão poderia exercer essa função, mas, para isso, ela precisa se constituir como uma instância, como um lugar e um tempo, onde e quando se possa experimentar a tomada de decisões coletivas e analisar situações com um grau de implicação maior em relação àquilo que é produzido (O nocko Campos, 2003c).

Portanto, seria necessário incorporar novas disciplinas na formação de gestores e planejadores que lhes permitissem entender as várias dimensões com que estão lidando na hora das decisões e conflitos no palco grupal, pois não se trata somente de criar espaços de fala e trocas auto-reflexivas que propiciariam a democratização e um grau de análise maior das prá- 
ticas, coisa de por si já importante. Trata-se de poder compreender também que esses espaços são freqüentemente lócus de apresentação de uma mise-en-scène de estados pulsionais inconscientes.

Oury destaca a importância de reconhecermos essa dimensão inconsciente nas relações detrabalho:

Ora, na própria equipe já existe uma forma de colocar em prática permanente as relações complementares, assim como as complementaridades (mas não as complementaridades tais como: "sou especialista nisso, ele naquilo, etc..."). Trata-se, com efeito, de um registro quase material: de um lado a articulação de diferentes competências, de outro as condi ções de uma certa forma de convivência. Aí existe uma armadilha: não se trata de uma complementaridade mais ou menos romântico-moderna, do gênero "estamos todos do mesmo lado", que se perde no especular, mas de uma complementaridade inconsciente (Oury, 1991).

\section{Gestão-subjetividade-clínica}

Q ual seria a saída para o SUS se não houvesse uma profunda reformulação da clínica que nele se pratica? Teria o Estado brasileiro as condições para financiar um sistema de caráter universal nos moldes, por exemplo, do modelo norte-americano? $\mathrm{E}$, ainda, imaginando que houvesse recursos sem fim, seria justo submeter a população a tal grau de medicalização, que beira a iatrogenia?

Recentemente, tem se reavivado o debate sobre a integralidade. É interessante esse ponto, pois durante anos a grande diretriz do SUS a ser conquistada foi a do acesso. E devemos reconhecer que houve avanços em relação ao acesso, contudo, muitas vezes se avançou sem interrogar acesso a quê (Onocko Campos, 2003a, 2003b).

$N$ a moda de finais dos anos 90 , no furor pe la eficiência e pelo Estado mínimo, praticamente se eliminou a discussão sobre a eficácia das práticas de saúde, e isso se viu agravado por um certo discurso pós-moderno que, amparado em um forte relativismo, desqualificou as análises técnicas.

Todavia, é preciso reconhecer - no caso dos encontros assistenciais, da clínica - que sempre haverá uma dimensão técnica do trabalho envolvida. 0 recalcamento de al gumas categorias é sempre interessante de ser interrogado. Por exemplo, o tema do cuidado tem sido muito abordado ultimamente. Entendo que vários autores procuram com isso chamar a atenção para a dimensão não técnica sempre (também) envolvida nos encontros assistenciais. Valorizar 0 aspecto intersubjetivo, comunicativo, as chamadas tecnologias leves (Artman, Azevedo \& Castilho Sá, 1997; Ayres, 2001; Rivera, 1995, 1996; M erhy, 1997). É essa uma questão premente e importante no desenfreado consumo de tecnologias duras que o mercado médico tem colocado, sem dúvida.

Porém, gostaríamos de chamar a atenção para o caráter de recalcado da categoria clínica. A psicanálise ensina-nos a ficar atentos àquilo que "não se fala". Eliminarmos a problematização sobre qual éa clínica que se faz nos equipamentos de saúde acarreta o risco de banalizarmos a importância dos aspectos técnicos do trabal ho. 0 que diferencia os trabal hadores de saúde do restante da população em termos de valor de uso (e de troca) de sua própria força de trabalho é a qualificação técnica eé, sempre, "um dado saber". M as, também, acarreta o risco de não problematizarmos a clínica como uma disciplina que, precisando sempre de uma sólida ancoragem teórica, não se esgota na sua dimensão técnica, devendo sempre ficar atenta à produção tanto de acolhimento quanto de desvio, como muito bem chamaram a atenção Passos \& Benevides (2001).

Trabalharmos em prol da transdisciplinaridade, buscarmos relações mais horizontalizadas de poder entre os diversos saberes (médico, popular, alternativos, psi, etc.) não nos deveria ofuscar o reconhecimento do avanço que o domínio de certa competência técnica traz à produção de saúde, no tratamento e reabilitação de algumas doenças. Sendo críticos com uma leitura tecnicista da saúde, porém, desejamos ressaltar que, a nosso ver, é fundamental não descartar a clínica e sua qualidade técnica, como se fosse o bebê com a água do banho.

Essa questão parece-nos central, inclusive, porque a definição de quais meios técnicos um dado trabalhador possui, ou não, na sua prática, será fundamental tanto para a eficácia dessas práticas quanto interferirá também no grau de resistência e tolerância com que o sujeito em questão conta para enfrentar o dia-a-dia em contato permanente com a dor e o sofrimento.

Deter o domínio de uma ou várias técnicas não é bom ou ruim em si. Segundo tentamos mostrar, dependendo do seu funcionamento, do tipo de processos de subjetivação que um 
dado equipamento favorece ou não, a técnica poderá se constituir em alavanca de novos processos criativos, abertos à diversidade, acolhedores da diferença; ou funcionar como receita prescritiva, guarda-chuva defensivo contra aquilo que no outro nos ameaça. M as isso não é uma qualidade da técnica, dependerá do contexto de experimentação da técnica em questão.

O ury destaca claramente esta função em relação à clínica:

(...) exige uma disposição particular que se adquire pelo exercício de uma "tekné", espécie de atenção trabalhada que a torna sensível á qualidade do contexto, à polifonia dos discursos, às manifestações paradoxais de um sentido iluminado. Aí está um dos objetivos fundamentais a que uma formação bem conduzida poderia se propor. Para desvendar tal ou tal forma de manifestação patológi ca é preci so estar "advertido". Problema banal semelhante à aprendizagem da escuta dos barulhos do coração: se não estamos preparados, não adianta escutá-los com 0 estetoscópio, pois não ouvimos senão ruídos confusos (Oury, 1991. Grifo nosso).

Digamos que o trabalhador de saúde que não conte com razoável formação técnica será submetido a mais um fator de sofrimento, a angústia que provoca o "nada saber", ou, no dizer de Oury, o fato de não estar advertido. Quando a insegurança técnica é grande, toda demanda é amplificada, não é possível discernir em relação a riscos e urgências. Tudo se torna tão intenso que, para aplacar essa angústia, tudo acaba por ser banalizado, caracterizando uma das formas da burocratização. Também, essa insegurança está por trás dos mecanismos que perpetuam certos usos do poder na instituição, como, por exemplo, o excessivo poder médico: se eu nada sei, suponho que outro saiba, delego a ele o saber e o poder... Por esses argumentos todos, consideramos os trabal hadores menos qualificados, do ponto de vista técnico, mais vulneráveis a sofrimento psíquico no contexto dos equipamentos do SU S que analisaremos a seguir.

Os conhecimentos técnicos teriam, na nossa argumentação, duas funções produtoras de eficácia: uma específica na produção de saúde dos usuários, e outra importante na produção de saúde dos trabalhadores. Eles poderiam ser a mola da ampliação da clínica (Campos, 2003), do resgate da dimensão do cuidado, da melhora nos processos intersubjetivos de comunicação, etc.

Cremos, portanto, que, em saúde, a ampliação da clínica é uma questão de eficácia do sis- tema e, sendo preciso diferenciar, é sempre necessário não separar, nem dissociar a questão clínica das formas de organização do trabalho e sua coordenação (gestão). E a gestão estará sempre entrelaçada às questões subjetivas.

\section{Por que gestão-subjetividade? 0 contato com o irrepresentável da miséria, no contemporâneo}

Detenhamo-nos brevemente, então, para analisar a que está exposto um trabal hador de saúde na periferia das grandes cidades brasileiras no contemporâneo, no SUS.

Se estar em contato significa expor-se a afetos e, portanto, a ser afetado, deveríamos pensar na realidade dos grandes bolsões de pobreza. Quem trabalha nesses locais sabe quão difícil resulta colocar-se em contato com tanta intensidade cotidianamente. $N$ ão estamos falando somente da já dura experiência (que podemos ter em qualquer hospital universitário) de conviver com a dor e a morte, o excesso de demanda, a falta de recursos.

0 grau de miserabilidade dessas populações extrapola nossa capacidade de resistência. U ma coisa é saber - em tese - que o Brasil é um país cheio de pobres. Outra bem diferente é tentar uma intervenção terapêutica com pessoas que estruturaram sua própria resistência à morte por meio de formas de subjetivação que não conseguimos compreender. U ma mãe que não demonstra preocupação com seu filho gravemente enfermo e mal nutrido. U m contexto em que vida e morte (tráfico, violência material e subjetiva) significam outra coisa e não a que estamos costumados a enten der. Desejamos destacar a intensidade dessa experiência e a sua singularidade. 0 grau de esgarçamento simbólico que percebemos em algumas dessas comunidades, nas quais, por exemplo, em vez de conversar, mata-se, coloca em xeque todas nossas propostas interpretativas. Falta-nos suporte, arcabouço conceitual ou categorial para a saúde coletiva poder de fato apoiar os seus agentes nesse percurso. É nessa busca que trabalhamos com a idéia da gestão como uma importante produtora de processos de subjetivação. A gestão como produtora de passagens, para dar cabida a tanta intensidade como há no trabal ho em saúde na rede pública.

Às vezes, afirma-se que os usuários não estão preocupados com os destinos do SUS, que estão desapropriados dele. Discordamos: eles 
não estão desapropriados do que lhes interessa ou daquilo que lhes diz respeito às suas próprias estratégias de sobrevivência. M ontar serviços de saúde, criar PSFs são estratégias nossas. Eles não têm de se apropriar. A mãe do menino desnutrido não está desapropriada de nada, ela inventa uma forma de resistir.

Por isso, a relação equipes/população deve ser mediada por oferecimentos (Campos, 2000). $U \mathrm{~m}$ oferecimento é como um cavalo encilhado passando. A nossa função é multiplicar as oportunidades para que algumas pessoas o montem. É uma questão ética: nós não saberíamos sobreviver a situações que vemos nos bolsões de pobreza das grandes cidades brasileiras. Eles sabem. Nós que temos muito de apreender. Nós só podemos ofertar nossa diferença, nosso estranhamento como um convite a experimentar outras formas de ser na comunidade. E não porque a nossa seja melhor, senão porque temos um compromisso ético em desviar a produção em larga escala de miseráveis. Tudo o que é vivo resiste. E muitas dessas comunidades inventaram estratégias muito eficazes de reprodução. De fato, vários séculos de Brasil não conseguiram eliminá-los. N ossa estratégia é desviar essa reprodução e colocá-la na trilha da produção do novo... Talvez seja a única coisa que nos dê um pouco de consistência.

N esse contexto, em publicações recentes, afortunadamente destaca-se a idéia da integralidade. E aí coloca-se a questão sobre qual o conceito de integralidade que permeia a clínica. É a integralidade dos encaminhamentos? $\mathrm{N}$ ada como um bom encaminhamento para nos proteger do estranhamento de pormo-nos em contato... Cada vez que um caso cria alguma angústia na equipe ele é encaminhado à outra, até que esta não agüente mais o medo, ou a sensação de impotência e assim vai... à deriva, derivado para sempre. Contudo, muitas equipes defensivamente chamariam isso de integralidade, pois sempre há para onde encaminhar. A integralidade está, a nosso ver, profundamente relacionada com a ampliação da clínica para além do puramente biológico, na direção dos riscos subjetivos e sociais (Campos, 2003).

É claro quenão estamos com isso desconhe cendo os gargalos do SUS. Em muitos locais não há para onde encaminhar, ou não há vagas para procedimentos importantes; esse continua a ser um entrave do sistema como macropolítica.

Contudo, a solução macropolítica, por si só, sempre será insuficiente (a oferta gerando cada vez mais demanda), se não operarmos desvios nas formas de produzir saúde. Por isso, sustentamos que a gestão tem um compromisso em dar um certo suporte, em criar instâncias de análise para as equipes. $M$ as isso no sentido psicanalítico, ajudando a compreender que o turbilhão de emoções que nos acompanha no trabalho é inseparável de nossa condição de humanidade. Como diz Kaës sofremos também, na instituição, por não compreendermos a causa, o objeto, o sentido e a própria razão do sofrimento que aí experimentamos (Kaës, 1991). Será que a gestão pode-nos ajudar nessa tarefa?

Cremos que isso não será possível na dimensão e escala que a realidade brasileira hoje nos demanda, se não nos valermos de alguns dispositivos para propiciar a tomada de consistência.

Diretrizes como as de responsabilização, resolutividade e acolhimento poderiam funcionar como uma espécie de operador lógico (Oury, 1991) para a reorganização dos serviços em prol da ampliação da clínica e da humanização da atenção à saúde.

Para conseguir operar com diretrizes como operadores lógicos (disparadores de análises e mudanças, e não como camisas de força ideológicas), seria necessário criar nos equipamentos uma certa ambiência. Ambiência que não dependeria de engenharias cosméticas nos prédios e salas de espera, porém, no dizer de Oury, seria constituída pelas "maneiras da civilização local que permitem acolher o insólito". Para esse autor:

(...) poder decifrar naquilo que se apresenta o que é importante acolher, e de qual maneira acolhêl $\mathbf{0}$. A função de acolhimento é a base de todo trabalho de agenciamento (...) Não se trata, certamente, de se contentar com uma resposta "tecnocrática" tal como função de acolhimento = hóspede de acol himento! 0 acol himento, sendo coletivo na sua textura, não se torna eficaz senão pela valorização da pura singularidade daqueleque éacolhido. Esse processo pode-se fazer progressivamente, por patamares, e às vezes não é senão ao fim de muitos meses que ele se torna eficaz para tal ou tal sujeito (...) à deriva (O ury, 1991. Grifo nosso).

Como vemos, tais mudanças desejáveis nos encontros assistenciais requerem intervenções complexas (no sentido do grande número de variáveis) e de grande investimento técnico, ético e político. Não acontecerão somente com boa vontade, não demoram somente por causa de falhas na comunicação, nem por "falta" de humanização. $M$ as bem acontecem por inevitável humanidade dos humanos ali envolvidos. 


\section{Volta à abordagem metodológica, da hermenêutica-crítica à narrativa política}

Gadamer (1997) coloca o tema da aplicação logo antes da discussão sobre saber ético e saber técnico. Ele afirma enfaticamente que seria falso pensar que com o desenvolvimento tecnológico poderíamos prescindir da reflexão ética. Pensamos que no bojo dessa discussão, ena sua el aboração sobre o destaque do objeto (lembrando que, para esse autor, são o presente e os interesses do pesquisador os que operam o "destaque"), está a questão da práxis. No universo gadameriano há sempre uma relação já existente entre linguagem e ação. Essa é a causa pela qual a hermenêutica está sempre em busca do sentido, à diferença de certos ramos da lingüística preocupados com a estrutura da linguagem.

Gadamer diz-nos: aquele que atua lida com coisas que nem sempre são como são, pois que são também diferentes (...) Seu saber deve orientar sempre seu fazer (1997). Parece nos importante destacar esse aspecto que vincula indissociavelmente a práxis à ética. Sempre que nos deparamos com dilemas éticos é em relação a alguma ação, raramente a um discurso. A retórica está salva dessas indagações, ou senão não existiriam os sofismos. À retórica interessa convencer enão a busca da verdade. D estarte, enquanto a retórica afirma, a hermenêutica interroga.

Recentemente Julia Kristeva, reflexionando sobre "as novas doenças da alma", interpelanos: Vocêtem uma alma? Essa pergunta - filosófica, teológica ou simplesmente incongruente encerra hoje uma nova dimensão. Confrontada aos neurolépticos, à aeróbica e ao massacre da mídia, a alma ainda existe? (2002a).

Para essa autora, toda interpretação é uma "revolta" (Kristeva, 2000). Na etimologia da palavra revolta, lembra-nos, está contida a acepção "rejeição da autoridade" (autores como Foucault e N ietzsche teriam concordado). Gadamer, na sua elaboração sobre o mundo do texto, afirma que não é fácil pensar que o que está escrito não seja verdade. 0 próprio movimento de fixação pela escrita outorga ao texto escrito um estatuto de autoridade. $M$ as, para ele, a autoridade é al go que aceita ser inspecionado e não uma submissão. É na volta à tradição, na escuta das múltiplas vozes com que ela nos fala que podemos achar a nossa própria voz.

Kristeva lembra-nos que somos indivíduos e há muito tempo. Houve de fato, na modernidade, diversas figuras da subjetividade e diver- sas modalidades do tempo. Dentre elas, a psicanálise nos diz que a felicidade só existe ao preço de uma revolta: A revolta que se revela acompanhando a experiência íntima da felicidade é parte integrante do princípio do prazer. Aliás, no plano social a ordem normalizadora está longe de ser perfeita e gera os excluídos (...) (Kristeva, 2000).

Portanto, esta autora chama-nos a atenção para a necessidade de uma cultura-revolta numa sociedade que vive, se desenvolve e não estagna. Para ela, quando essa cultura não existe, a vida transforma-se em uma vida de morte, de violência física e mortal, de barbárie. Não é interessante, neste momento, voltar a refletir sobre a periferia das grandes cidades brasileiras, as relações equipes-usuários que tentamos mapear acima, e a formulação de políticas públicas à luz das questões trazidas por Kristeva?

Tenho dúvidas sobre se a palavra barbárie, oferecida pela autora, seja a mais apropriada para se pensar na miséria brasileira. Contudo, carecendo de maior criatividade, penso que pelo menos seria uma tentativa de tirar a situação de seu caráter inominável. Parece- me que poderíamos aceitar uma frase do tipo: a produção em larga escala de miseráveis no Brasil constitui-se em uma barbárie.

0 dicionário diz que barbárie vem de barbaria "selvageria, crueldade, atrocidade, barbaridade, barbarismo". Talvez devamos dizer, narrar de novo e de outra forma essa atrocidade que no contemporâneo se apresenta naturalizada. Sabemos que é produzida, não é "natural". E é preciso uma certa revolta para poder recuperar a "experiência íntima de felicidade" no laço social. O peração que só pode acontecer no "interesse": entrea palavra e a ação (Kristeva, 2002b).

Para essa autora, o "inter-esse" é próprio da política, e assim ela volta a colocar em contato a narrativa e a política: É pela narrativa, e não pela língua em si (quenão lheperdura menos como via e passagem) que se realiza o pensamento político (Kristeva, 2002b). Lembra-nos com isso que a narrativa é sempre memória da ação e estranheza incessante. A ação nunca é possível no isolamento desde que sempre estará inserida no mundo social. Portanto, seria preciso ainda fazer uma outra tarefa: U Itrapassar a noção de texto, (...) H ei de me esforçar para introduzir, em seu lugar, a noção de experiência, que compreende o princípio de prazer e o de renascimento de um sentido para o outro, eque só seria possível compreender à luz da experiência-revolta (Kristeva, 2000). 
Experiência que, para essa autora, a psicanálise poderia propiciar a cada sujeito humano individualmente.

Tentamos alinhavar uma narrativa que argumenta que a psicanál ise também teria uma contribuição a dar no contexto da saúde coletiva brasileira, dos encontros entre trabalhadores e usuários, e nas instâncias de gestão do cotidiano. Procuramos mostrar as potencialidades que algumas categorias da psicanálise poderiam trazer para os nossos serviços de saúde. 0 de um reconhecimento de um sentido para 0 outro que não se baseie no recal que de nossa afetividade, que possa aceitar um certo grau de mal-estar, precisamente porque inserido no laço social.

$\mathrm{E}$, na trilha aberta por Kristeva, autorizarnos-íamos a dizer que o que traz para o texto sua dimensão ética é constituir-se em uma narrativa política, al iás, única maneira de constituir uma memória organizada desde os tempos de Péricles. Assim, queremos deixar nossa contribuição na Saúde Coletiva brasileira, nossa maneira de responder metodológica, teórica e praticamente à pergunta de Kristeva: sim, ainda temos uma luta e uma alma.

\section{Referências bibliográficas}

Arouca S 2003. O dilema preventivista, (1975). U nespFiocruz, São Paulo-Rio de Janeiro.

Artman E, Azevedo C \& Castilho Sá M 1997. Possibilidades de aplicação do enfoque estratégico do planejamento no nível local de saúde: análise comparada de duas experiências. Cadernos de Saúde Pública 13(4):723-740.

Ayres R 2001. Sujeito, intersubjetividade e práticas em saúde. Ciência e Saúde Coletiva 6(1):63-72.

Benasayag M \& Charlton E 1993. Esta dulce certidumbre de lo peor. Editora Nueva Visión, Buenos Aires.

Birman J 1980. Enfermidade eloucura. Editora Campus, Rio de Janeiro.

Burlandy L \& Bodstein RCA 1998. Política e saúde coletiva: reflexão sobre a produção científica (1976-1992). Cadernos de Saúde Pública 14(3):543-554

Campos GWS 1991. A saúde pública e a defesa da vida. Hucitec, São Paulo.

Campos GWS 1994. Considerações sobre a arte e a ciência da mudança: revolução das coisas e reforma das pessoas. 0 caso da saúde, pp. 29-88. In Cecílio (org.). Inventando a mudança na saúde. Hucitec, São Paulo.

Campos GWS 2000. U m método para análise e co-gestão de coletivos. Hucitec, São Paulo.

Campos GWS 2003. A clínica do sujeito: por uma clínica reformulada e ampliada, pp. 51-67. In G Campos. Saúde paidéia. Hucitec, São Paulo.

Carvalho SR 2002. Saúde coletiva e promoção à saúde: uma reflexão sobre os temas do sujeito e da mudança. Tese de doutorado. DM PS/FCM/Unicamp, Campinas.

Carvalho IM 2003. Educação física e saúde coletiva: uma introdução, pp. 19-36. In M Luz. N ovos saberes e prática em saúde coletiva. Hucitec, São Paulo. 
Donnangelo C 1975. M edicina e sociedade. Pioneira, São Paulo.

Enriquez E 1997. A organização em análise. Editora Vozes, Petrópolis.

Ferreira ABH 1997. Dicionário Aurélio da Língua Portuguesa. CD-ROM. Editora Nova Fronteira, Rio de Janeiro.

Figueiredo AC 1997. Vastas confusões e atendimentos imperfeitos: a clínica psicanalítica no ambulatório público. Relume-Dumará, Rio de Janeiro.

Fleury S 1992. Saúde: coletiva? Q uestionando a onipotência do social. Relume-Dumará, Rio de Janeiro.

Freud S 1997. O mal-estar na civilização (1931). Edição eletrônica brasileira das obras psicológicas completas de Sigmund Freud (CD-Rom). Imago Editora, Rio de Janeiro.

Freud S 1975. Construções em análise (1937), pp. 289304. In S Freud. Edição standard brasileira das obras psicológicas completas de Sigmund Freud, V. XXIII. Imago Editora, Rio de Janeiro.

Furtado JP \& Onocko Campos R 2005. A transposição das políticas de saúde mental no Brasil para a prática nos novos serviços. Revista Latino-americana de Psicopatologia Fundamental VIII(1):109-122.

Gadamer HG 1997. Verdade e método: traços fundamentais de uma hermenêutica filosófica. Tradução de Flávio M eurer. Editora Vozes, Petrópolis.

Gonçalvez RBM 1994. Tecnologia e organização social das práticas de saúde. Hucitec-Abrasco, São Paulo-Rio de Janeiro.

Kaës R1991. Realidade psíquica e sofrimento nas instituições, pp. 1-39. In R Kaës, J Bleger, E Enriquez, F Fornari, P Fustier, R Roussillon \& JP Vidal (orgs.). A instituição e as instituições. Tradução de Joaquim Pereira N eto. Casa do Psicólogo, São Paulo.

Kristeva J 2002a. As novas doenças da alma. Tradução de Joana Angélica d'A vila M elo. Rocco Editora, Rio de Janeiro.

Kristeva 2002b. 0 gênio feminino: a vida, a loucura, as palavras. H anna Arednt, Tomo I. Tradução de Eduardo Francisco Alves. Rocco Editora, Rio de Janeiro.

Kristeva J 2000. Sentido e contra-senso da revolta: poderes e limites da psicanálise I. Tradução de Ana Maria Scherer. Rocco Editora, Rio de Janeiro.

Kuhn T 1997. A estrutura das revoluções científicas. Tradução de Beatriz Boeira \& N elson Boeira. Editora Perspectiva, São Paulo.

L'A batte S 2003. A análise institucional e a saúde coletiva. Ciência e Saúde Coletiva 8(1):265-274.

Luz M 2000. A produção científica em ciências sociais e saúde: notas preliminares. Saúde em D ebate 24(55): 54-68.
Menendez E 1992. Grupo doméstico y proceso de salud/ enfermedad/ atención. Del teoricismo al movimiento contínuo. Cuadernos M édico Sociales 59:3-18.

M erhy EE 1997. Em busca do tempo perdido: a micropolítica do trabalho vivo, pp. 71-112. In EE M erhy \& R Onocko Campos (orgs.). Agir em saúde. Hucitec, São Paulo.

M inayo M C (org.) 1995. Os muitos brasis, saúde e população na década de oitenta. Hucitec-A brasco, São Paulo-Rio de Janeiro.

M otta FCP \& Freitas M E 2000. Vida psíquica e organização. Editora FGV, Rio de Janeiro.

Onocko Campos R 2003a. O planejamento no labirinto: uma viagem hermenêutica. Hucitec, São Paulo.

Onocko Campos 2003b. Planejamento em saúde: a armadilha da dicotomia público-privado. RAP - Revista de Administração Pública 37(2):189-200.

Onocko Campos 2003c. A gestão: espaço de intervenção, análise e especificidades técnicas, pp. 122-149. In G Campos. Saúde paidéia. Hucitec, São Paulo.

Oury J 1991. Itinerários de formação. Revue Pratique 1: 42-50.

Passos E \& Benevides R 2001. Clínica e biopolítica na experiência do contemporâneo. Revista de Psicologia Clínica PU C/RJ 13(1):89-100.

Pitta A 1990. H ospital dor e morte como ofício. Hucitec, São Paulo.

Ricoeur P 1990. Interpretação e ideologias. Tradução de Hilton Japiassu. Francisco Alves Editora, Rio de Janeiro.

Ricoeur P 1997. Tempo e narrativa. Tomo I. Tradução de Constança M arcondes César. Papirus, Campinas.

Rivera FJU 1995. Agir comunicativo e planejamento social. Fiocruz, Rio de Janeiro.

Rivera FJU 1996. A gestão situacional (em saúde) e a organização comunicante. Cadernos de Saúde Pública 12(3):357-372.

Rodriguez EBC 1993. As subjetividades em revolta - Institucionalismo francês e novas análises. Dissertação de mestrado. Instituto de M edicina Social, UERJ, Rio de Janeiro.

Roudinesco E \& Plon M 1998. Dicionário de Psicanálise. Tradução Vera Riveiro. Jorge Zahar, Rio de Janeiro.

Vasconcelos CM 2005. Os paradoxos do SUS. Tese de doutorado. DM PS/FCM/U nicamp, Campinas.

Data de apresentação em 14/03/2005

Aprovado em 19/04/2005

Versão final apresentada em 5/05/2005 